\title{
A new common coupled fixed point theorem in generalized metric space and applications to integral equations
}

\section{Feng $\mathrm{Gu}^{*}$ and Yun Yin}

\section{"Correspondence: \\ gufeng99@sohu.com \\ Department of Mathematics, Institute of Applied Mathematics, Hangzhou Normal University, Hangzhou, Zhejiang 310036, China}

\begin{abstract}
In the present paper, we prove a common coupled fixed point theorem in the setting of a generalized metric space in the sense of Mustafa and Sims. Our results improve and extend the corresponding results of Shatanawi. We also present an application to integral equations.
\end{abstract}

Keywords: G-metric space; common coupled coincidence fixed point; common fixed point; integral equation

\section{Introduction and preliminaries}

The study of fixed points of mappings satisfying certain contractive conditions has been in the center of rigorous research activity. For a survey of common fixed point theory in metric and cone metric spaces, we refer the reader to [1-9]. In 2006, Bhaskar and Lakshmikantham [10] initiated the study of a coupled fixed point in ordered metric spaces and applied their results to prove the existence and uniqueness of solutions for a periodic boundary value problem. For more works in coupled and coincidence point theorems, we refer the reader to [11-13].

Some authors generalized the concept of metric spaces in different ways. Mustafa and Sims [14] introduced the notion of G-metric space, in which the real number is assigned to every triplet of an arbitrary set as a generalization of the notion of metric spaces. Based on the notion of G-metric spaces, many authors (for example, [15-33]) obtained some fixed point and common fixed point theorems for mappings satisfying various contractive conditions. Fixed point problems have also been considered in partially ordered G-metric spaces [34-39].

The purpose of this paper is to obtain some common coupled coincidence point theorems in G-metric spaces satisfying some contractive conditions.

The following definitions and results will be needed in the sequel.

Definition 1.1 [14] Let $X$ be a nonempty set, and let $G: X \times X \times X \rightarrow R^{+}$be a function satisfying the following axioms:

(G1) $G(x, y, z)=0$ if $x=y=z$;

(G2) $0<G(x, x, y)$ for all $x, y \in X$ with $x \neq y$;

(G3) $G(x, x, y) \leq G(x, y, z)$ for all $x, y, z \in X$ with $z \neq y$;

02013 Gu and Yin: licensee Springer. This is an Open Access article distributed under the terms of the Creative Commons Attribution License (http://creativecommons.org/licenses/by/2.0), which permits unrestricted use, distribution, and reproduction in any medium, provided the original work is properly cited. 
(G4) $G(x, y, z)=G(x, z, y)=G(y, z, x)=\cdots$ (symmetry in all three variables);

(G5) $G(x, y, z) \leq G(x, a, a)+G(a, y, z)$ for all $x, y, z, a \in X$ (rectangle inequality), then the function $G$ is called a generalized metric, or more specifically, a $G$-metric on $X$, and the pair $(X, G)$ is called a $G$-metric space.

Definition 1.2 [14] Let $(X, G)$ be a $G$-metric space, and let $\left\{x_{n}\right\}$ be a sequence of points in $X$, a point $x$ in $X$ is said to be the limit of the sequence $\left\{x_{n}\right\} \operatorname{if}_{m, n \rightarrow \infty} G\left(x, x_{n}, x_{m}\right)=0$, and one says that the sequence $\left\{x_{n}\right\}$ is G-convergent to $x$.

Thus, if $x_{n} \rightarrow x$ in a $G$-metric space $(X, G)$, then for any $\epsilon>0$, there exists $N \in \mathbb{N}$ such that $G\left(x, x_{n}, x_{m}\right)<\epsilon$ for all $n, m \geq N$.

Proposition 1.3 [14] Let $(X, G)$ be a G-metric space, then the following are equivalent:

(1) $\left\{x_{n}\right\}$ is G-convergent to $x$.

(2) $G\left(x_{n}, x_{n}, x\right) \rightarrow 0$ as $n \rightarrow \infty$.

(3) $G\left(x_{n}, x, x\right) \rightarrow 0$ as $n \rightarrow \infty$.

(4) $G\left(x_{n}, x_{m}, x\right) \rightarrow 0$ as $n, m \rightarrow \infty$.

Definition 1.4 [14] Let $(X, G)$ be a $G$-metric space. A sequence $\left\{x_{n}\right\}$ is called $G$-Cauchy sequence if for each $\epsilon>0$, there exists a positive integer $N \in \mathbb{N}$ such that $G\left(x_{n}, x_{m}, x_{l}\right)<\epsilon$ for all $n, m, l \geq N$; i.e., if $G\left(x_{n}, x_{m}, x_{l}\right) \rightarrow 0$ as $n, m, l \rightarrow \infty$.

Definition 1.5 [14] A G-metric space $(X, G)$ is said to be $G$-complete if every $G$-Cauchy sequence in $(X, G)$ is $G$-convergent in $X$.

Proposition 1.6 [14] Let $(X, G)$ be a G-metric space, then the following are equivalent:

(1) The sequence $\left\{x_{n}\right\}$ is G-Cauchy.

(2) For every $\epsilon>0$, there exists $k \in \mathbb{N}$ such that $G\left(x_{n}, x_{m}, x_{m}\right)<\epsilon$ for all $n, m \geq k$.

Proposition 1.7 [14] Let $(X, G)$ be a G-metric space. Then the function $G(x, y, z)$ is jointly continuous in all three of its variables.

Definition $1.8[14]$ Let $(X, G)$ and $\left(X^{\prime}, G^{\prime}\right)$ be $G$-metric space, and let $f:(X, G) \rightarrow\left(X^{\prime}, G^{\prime}\right)$ be a function. Then $f$ is said to be $G$-continuous at a point $a \in X$ if and only if for every $\epsilon>0$, there is $\delta>0$ such that $x, y \in X$ and $G(a, x, y)<\delta$ implies that $G^{\prime}(f(a), f(x), f(y))<\epsilon$. A function $f$ is $G$-continuous at $X$ if and only if it is $G$-continuous at all $a \in X$.

Proposition 1.9 [14] Let $(X, G)$ and $\left(X^{\prime}, G^{\prime}\right)$ be G-metric spaces, then a function $f: X \rightarrow X^{\prime}$ is $G$-continuous at a point $x \in X$ if and only if it is $G$-sequentially continuous at $x$; that is, whenever $\left(x_{n}\right)$ is G-convergent to $x,\left(f\left(x_{n}\right)\right)$ is G-convergent to $f(x)$.

Proposition 1.10 [14] Let $(X, G)$ be a G-metric space. Then for any $x, y, z$, a in $X$, it follows that

(i) if $G(x, y, z)=0$, then $x=y=z$;

(ii) $G(x, y, z) \leq G(x, x, y)+G(x, x, z)$;

(iii) $G(x, y, y) \leq 2 G(y, x, x)$;

(iv) $G(x, y, z) \leq G(x, a, z)+G(a, y, z)$; 
(v) $G(x, y, z) \leq \frac{2}{3}(G(x, y, a)+G(x, a, z)+G(a, y, z))$;

(vi) $G(x, y, z) \leq G(x, a, a)+G(y, a, a)+G(z, a, a)$.

Definition 1.11 [10] An element $(x, y) \in X \times X$ is called a coupled fixed point of a mapping $F: X \times X \rightarrow X$ if $F(x, y)=x$ and $F(y, x)=y$.

Definition 1.12 [11] An element $(x, y) \in X \times X$ is called a coupled coincidence point of the mappings $F: X \times X \rightarrow X$ and $g: X \rightarrow X$ if $F(x, y)=g x$ and $F(y, x)=g y$.

Definition 1.13 [11] Let $X$ be a nonempty set. Then we say that the mappings $F: X \times X \rightarrow$ $X$ and $g: X \rightarrow X$ are commutative if $g F(x, y)=F(g x, g y)$.

\section{Main results}

We start our work by proving the following crucial lemma.

Lemma 2.1 Let $(X, G)$ be a G-metric space. Let $F_{1}, F_{2}, F_{3}: X \times X \rightarrow X$ and $g: X \rightarrow X$ be four mappings such that

$$
\begin{aligned}
G\left(F_{1}(x, y), F_{2}(u, v), F_{3}(w, z)\right) \leq & a_{1} G(g x, g u, g w)+a_{2} G(g y, g v, g z)+a_{3} G(g x, g u, g u) \\
& +a_{4} G(g y, g v, g v)+a_{5} G(g u, g w, g w)+a_{6} G(g v, g z, g z) \\
& +a_{7} G(g w, g x, g x)+a_{8} G(g z, g y, g y)
\end{aligned}
$$

for all $x, y, u, v, w, z \in X$, where $a_{i} \geq 0, i=1,2, \ldots, 8$ and $a_{1}+a_{2}+a_{3}+a_{4}+a_{7}+a_{8}<1$. Suppose that $(x, y)$ is a common coupled coincidence point of the mappings pair $\left(F_{1}, g\right),\left(F_{2}, g\right)$ and $\left(F_{3}, g\right)$. Then

$$
F_{1}(x, y)=F_{2}(x, y)=F_{3}(x, y)=g x=g y=F_{1}(y, x)=F_{2}(y, x)=F_{3}(y, x) .
$$

Proof Since $(x, y)$ is a common coupled coincidence point of the mappings pair $\left(F_{1}, g\right)$, $\left(F_{2}, g\right)$ and $\left(F_{3}, g\right)$, we have $g x=F_{1}(x, y)=F_{2}(x, y)=F_{3}(x, y)$ and $g y=F_{1}(y, x)=F_{2}(y, x)=$ $F_{3}(y, x)$. Assume that $g x \neq g y$. Then by $(2.1)$, we get

$$
\begin{aligned}
G(g x, g y, g y)= & G\left(F_{1}(x, y), F_{2}(y, x), F_{3}(y, x)\right) \\
\leq & a_{1} G(g x, g y, g y)+a_{2} G(g y, g x, g x)+a_{3} G(g x, g y, g y)+a_{4} G(g y, g x, g x) \\
& +a_{5} G(g y, g y, g y)+a_{6} G(g x, g x, g x)+a_{7} G(g y, g x, g x)+a_{8} G(g x, g y, g y) \\
= & \left(a_{1}+a_{3}+a_{8}\right) G(g x, g y, g y)+\left(a_{2}+a_{4}+a_{7}\right) G(g y, g x, g x) .
\end{aligned}
$$

Also by (2.1), we have

$$
\begin{aligned}
G(g y, g x, g x)= & G\left(F_{1}(y, x), F_{2}(x, y), F_{3}(x, y)\right) \\
\leq & a_{1} G(g y, g x, g x)+a_{2} G(g x, g y, g y)+a_{3} G(g y, g x, g x)+a_{4} G(g x, g y, g y) \\
& +a_{5} G(g x, g x, g x)+a_{6} G(g y, g y, g y)+a_{7} G(g x, g y, g y)+a_{8} G(g y, g x, g x) \\
= & \left(a_{1}+a_{3}+a_{8}\right) G(g y, g x, g x)+\left(a_{2}+a_{4}+a_{7}\right) G(g x, g y, g y) .
\end{aligned}
$$


Therefore,

$$
\begin{aligned}
& G(g x, g y, g y)+G(g y, g x, g x) \\
& \quad \leq\left(a_{1}+a_{2}+a_{3}+a_{4}+a_{7}+a_{8}\right)[G(g x, g y, g y)+G(g y, g x, g x)] .
\end{aligned}
$$

Since $0 \leq a_{1}+a_{2}+a_{3}+a_{4}+a_{7}+a_{8}<1$, we get

$$
G(g x, g y, g y)+G(g y, g x, g x)<G(g x, g y, g y)+G(g y, g x, g x)
$$

which is a contradiction. So, $g x=g y$, and hence,

$$
F_{1}(x, y)=F_{2}(x, y)=F_{3}(x, y)=g x=g y=F_{1}(y, x)=F_{2}(y, x)=F_{3}(y, x) .
$$

Theorem 2.1 Let $(X, G)$ be a G-metric space. Let $F_{1}, F_{2}, F_{3}: X \times X \rightarrow X$ and $g: X \rightarrow X$ be four mappings such that

$$
\begin{aligned}
G\left(F_{1}(x, y), F_{2}(u, v), F_{3}(w, z)\right) \leq & a_{1} G(g x, g u, g w)+a_{2} G(g y, g v, g z)+a_{3} G(g x, g u, g u) \\
& +a_{4} G(g y, g v, g v)+a_{5} G(g u, g w, g w)+a_{6} G(g v, g z, g z) \\
& +a_{7} G(g w, g x, g x)+a_{8} G(g z, g y, g y)
\end{aligned}
$$

for all $x, y, u, v, w, z \in X$, where $a_{i} \geq 0, i=1,2, \ldots, 8$ and $a_{1}+a_{2}+a_{3}+a_{4}+2 a_{5}+2 a_{6}+a_{7}+$ $a_{8}<1$. Suppose that $F_{1}, F_{2}, F_{3}$ and $g$ satisfy the following conditions:

(i) $F_{1}(X \times X) \subseteq g X, F_{2}(X \times X) \subseteq g X, F_{3}(X \times X) \subseteq g X$;

(ii) $g X$ is G-complete;

(iii) $g$ is G-continuous and commutes with $F_{1}, F_{2}, F_{3}$.

Then there exist unique $x \in X$ such that

$$
g x=F_{1}(x, x)=F_{2}(x, x)=F_{3}(x, x)=x .
$$

Proof Let $x_{0}, y_{0} \in X$. Since $F_{1}(X \times X) \subseteq g X, F_{2}(X \times X) \subseteq g X, F_{3}(X \times X) \subseteq g X$, we can choose $x_{1}, x_{2}, x_{3}, y_{1}, y_{2}, y_{3} \in X$ such that $g x_{1}=F_{1}\left(x_{0}, y_{0}\right), g y_{1}=F_{1}\left(y_{0}, x_{0}\right), g x_{2}=F_{2}\left(x_{1}, y_{1}\right)$, $g y_{2}=F_{2}\left(y_{1}, x_{1}\right), g x_{3}=F_{3}\left(x_{2}, y_{2}\right)$ and $g y_{3}=F_{3}\left(y_{2}, x_{2}\right)$. Combining this process, we can construct two sequences $\left\{x_{n}\right\}$ and $\left\{y_{n}\right\}$ in $X$ such that

$$
\begin{aligned}
& g x_{3 n}=F_{3}\left(x_{3 n-1}, y_{3 n-1}\right), \quad g y_{3 n}=F_{3}\left(y_{3 n-1}, x_{3 n-1}\right), \quad n=1,2,3, \ldots, \\
& g x_{3 n+1}=F_{1}\left(x_{3 n}, y_{3 n}\right), \quad g y_{3 n+1}=F_{1}\left(y_{3 n}, x_{3 n}\right), \quad n=0,1,2,3, \ldots, \\
& g x_{3 n+2}=F_{2}\left(x_{3 n+1}, y_{3 n+1}\right), \quad g y_{3 n+2}=F_{2}\left(y_{3 n+1}, x_{3 n+1}\right), \quad n=0,1,2,3, \ldots .
\end{aligned}
$$

If $g x_{3 n}=g x_{3 n+1}$, then $g x=F_{1}(x, y)$, where $x=x_{3 n}, y=y_{3 n}$. If $g x_{3 n+1}=g x_{3 n+2}$, then $g x=$ $F_{2}(x, y)$, where $x=x_{3 n+1}, y=y_{3 n+1}$. If $g x_{3 n+2}=g x_{3 n+3}$, then $g x=F_{3}(x, y)$, where $x=x_{3 n+2}$, $y=y_{3 n+2}$. On the other hand, if $g y_{3 n}=g y_{3 n+1}$, then $g y=F_{1}(y, x)$, where $y=y_{3 n}, x=x_{3 n}$. If $g y_{3 n+1}=g y_{3 n+2}$, then $g y=F_{2}(y, x)$, where $y=y_{3 n+1}, x=x_{3 n+1}$. If $g y_{3 n+2}=g y_{3 n+3}$, then $g y=$ $F_{3}(y, x)$, where $y=y_{3 n+2}, x=x_{3 n+2}$. Without loss of generality, we can assume that $g x_{n} \neq$ $g x_{n+1}$ and $g y_{n} \neq g y_{n+1}$, for all $n=0,1,2, \ldots$. 
By (2.2) and (G3), we have

$$
\begin{aligned}
G\left(g x_{3 n}, g x_{3 n+1}, g x_{3 n+2}\right)= & G\left(F_{3}\left(x_{3 n-1}, y_{3 n-1}\right), F_{1}\left(x_{3 n}, y_{3 n}\right), F_{2}\left(x_{3 n+1}, y_{3 n+1}\right)\right) \\
= & G\left(F_{1}\left(x_{3 n}, y_{3 n}\right), F_{2}\left(x_{3 n+1}, y_{3 n+1}\right), F_{3}\left(x_{3 n-1}, y_{3 n-1}\right)\right) \\
\leq & a_{1} G\left(g x_{3 n}, g x_{3 n+1}, g x_{3 n-1}\right)+a_{2} G\left(g y_{3 n}, g y_{3 n+1}, g y_{3 n-1}\right) \\
& +a_{3} G\left(g x_{3 n}, g x_{3 n+1}, g x_{3 n+1}\right)+a_{4} G\left(g y_{3 n}, g y_{3 n+1}, g y_{3 n+1}\right) \\
& +a_{5} G\left(g x_{3 n+1}, g x_{3 n-1}, g x_{3 n-1}\right)+a_{6} G\left(g y_{3 n+1}, g y_{3 n-1}, g y_{3 n-1}\right) \\
& +a_{7} G\left(g x_{3 n-1}, g x_{3 n}, g x_{3 n}\right)+a_{8} G\left(g y_{3 n-1}, g y_{3 n}, g y_{3 n}\right) \\
\leq & \left(a_{1}+a_{3}+a_{5}+a_{7}\right) G\left(g x_{3 n-1}, g x_{3 n}, g x_{3 n+1}\right) \\
& +\left(a_{2}+a_{4}+a_{6}+a_{8}\right) G\left(g y_{3 n-1}, g y_{3 n}, g y_{3 n+1}\right) .
\end{aligned}
$$

Similarly, we have

$$
\begin{aligned}
G\left(g y_{3 n}, g y_{3 n+1}, g y_{3 n+2}\right) \leq & \left(a_{1}+a_{3}+a_{5}+a_{7}\right) G\left(g y_{3 n-1}, g y_{3 n}, g y_{3 n+1}\right) \\
& +\left(a_{2}+a_{4}+a_{6}+a_{8}\right) G\left(g x_{3 n-1}, g x_{3 n}, g x_{3 n+1}\right) .
\end{aligned}
$$

By combining (2.3) and (2.4), we get

$$
\begin{aligned}
& G\left(g x_{3 n}, g x_{3 n+1}, g x_{3 n+2}\right)+G\left(g y_{3 n}, g y_{3 n+1}, g y_{3 n+2}\right) \\
& \quad \leq\left(\sum_{i=1}^{8} a_{i}\right)\left[G\left(g x_{3 n-1}, g x_{3 n}, g x_{3 n+1}\right)+G\left(g y_{3 n-1}, g y_{3 n}, g y_{3 n+1}\right)\right] .
\end{aligned}
$$

In the same way, we can show that

$$
\begin{aligned}
& G\left(g x_{3 n-1}, g x_{3 n}, g x_{3 n+1}\right)+G\left(g y_{3 n-1}, g y_{3 n}, g y_{3 n+1}\right) \\
& \quad \leq\left(\sum_{i=1}^{8} a_{i}\right)\left[G\left(g x_{3 n-2}, g x_{3 n-1}, g x_{3 n}\right)+G\left(g y_{3 n-2}, g y_{3 n-1}, g y_{3 n}\right)\right]
\end{aligned}
$$

and

$$
\begin{aligned}
& G\left(g x_{3 n-2}, g x_{3 n-1}, g x_{3 n}\right)+G\left(g y_{3 n-2}, g y_{3 n-1}, g y_{3 n}\right) \\
& \quad \leq\left(\sum_{i=1}^{8} a_{i}\right)\left[G\left(g x_{3 n-3}, g x_{3 n-2}, g x_{3 n-1}\right)+G\left(g y_{3 n-3}, g y_{3 n-2}, g y_{3 n-1}\right)\right] .
\end{aligned}
$$

It follows from (2.5), (2.6) and (2.7) that for all $n \in \mathbb{N}$, we have

$$
\begin{aligned}
& G\left(g x_{n}, g x_{n+1}, g x_{n+2}\right)+G\left(g y_{n}, g y_{n+1}, g y_{n+2}\right) \\
& \quad \leq\left(\sum_{i=1}^{8} a_{i}\right)\left[G\left(g x_{n-1}, g x_{n}, g x_{n+1}\right)+G\left(g y_{n-1}, g y_{n}, g y_{n+1}\right)\right] \\
& \quad=k\left[G\left(g x_{n-1}, g x_{n}, g x_{n+1}\right)+G\left(g y_{n-1}, g y_{n}, g y_{n+1}\right)\right]
\end{aligned}
$$




$$
\begin{aligned}
\leq & k^{2}\left[G\left(g x_{n-2}, g x_{n-1}, g x_{n}\right)+G\left(g y_{n-2}, g y_{n-1}, g y_{n}\right)\right] \\
& \vdots \\
\leq & k^{n}\left[G\left(g x_{0}, g x_{1}, g x_{2}\right)+G\left(g y_{0}, g y_{1}, g y_{2}\right)\right] .
\end{aligned}
$$

Where $k=\sum_{i=1}^{8} a_{i} \in[0,1)$. From (G3), we have $G\left(g x_{n}, g x_{n+1}, g x_{n+1}\right) \leq G\left(g x_{n}, g x_{n+1}, g x_{n+2}\right)$ and $G\left(g y_{n}, g y_{n+1}, g y_{n+1}\right) \leq G\left(g y_{n}, g y_{n+1}, g y_{n+2}\right)$. Hence, by the (G3) and (2.8), we get

$$
\begin{aligned}
& G\left(g x_{n}, g x_{n+1}, g x_{n+1}\right)+G\left(g y_{n}, g y_{n+1}, g y_{n+1}\right) \\
& \quad \leq G\left(g x_{n}, g x_{n+1}, g x_{n+2}\right)+G\left(g y_{n}, g y_{n+1}, g y_{n+2}\right) \\
& \quad \leq k^{n}\left[G\left(g x_{0}, g x_{1}, g x_{2}\right)+G\left(g y_{0}, g y_{1}, g y_{2}\right)\right] .
\end{aligned}
$$

Therefore, for all $n, m \in \mathbb{N}, n<m$, by (G5) and (2.9), we have

$$
\begin{aligned}
& G\left(g x_{n}, g x_{m}, g x_{m}\right)+G\left(g y_{n}, g y_{m}, g y_{m}\right) \\
& \leq {\left[G\left(g x_{n}, g x_{n+1}, g x_{n+1}\right)+G\left(g y_{n}, g y_{n+1}, g y_{n+1}\right)\right] } \\
&+\left[G\left(g x_{n+1}, g x_{n+2}, g x_{n+2}\right)+G\left(g y_{n+1}, g y_{n+2}, g y_{n+2}\right)\right] \\
&+\cdots+\left[G\left(g x_{m-1}, g x_{m}, g x_{m}\right)+G\left(g y_{m-1}, g y_{m}, g y_{m}\right)\right] \\
& \leq\left(k^{n}+k^{n+1}+\cdots+k^{m-1}\right)\left[G\left(g x_{0}, g x_{1}, g x_{2}\right)+G\left(g y_{0}, g y_{1}, g y_{2}\right)\right] \\
& \leq \frac{k^{n}}{1-k}\left[G\left(g x_{0}, g x_{1}, g x_{2}\right)+G\left(g y_{0}, g y_{1}, g y_{2}\right)\right] \rightarrow 0 \quad \text { as } n, m \rightarrow \infty .
\end{aligned}
$$

Which implies that

$$
G\left(g x_{n}, g x_{m}, g x_{m}\right) \rightarrow 0 \quad \text { and } \quad G\left(g y_{n}, g y_{m}, g y_{m}\right) \rightarrow 0 \quad \text { as } n, m \rightarrow \infty .
$$

Thus, $\left\{g x_{n}\right\}$ and $\left\{g y_{n}\right\}$ are all G-Cauchy in $g X$. Since $g X$ is $G$-complete, we get that $\left\{g x_{n}\right\}$ and $\left\{g y_{n}\right\}$ are $G$-convergent to some $x \in g X$ and $y \in g X$, respectively. Since $g$ is $G$-continuous, we have $\left\{g g x_{n}\right\}$ is $G$-convergent to $g x$ and $\left\{g g y_{n}\right\}$ is G-convergent to $g y$. That is,

$$
g g x_{n} \rightarrow g x \text { and } \quad g g y_{n} \rightarrow g y \quad \text { as } n \rightarrow \infty .
$$

Also, since $g$ commutes with $F_{1}, F_{2}$ and $F_{3}$, respectively, we have

$$
\begin{aligned}
& g g x_{3 n}=g F_{3}\left(x_{3 n-1}, y_{3 n-1}\right)=F_{3}\left(g x_{3 n-1}, g y_{3 n-1}\right), \\
& g g y_{3 n}=g F_{3}\left(y_{3 n-1}, x_{3 n-1}\right)=F_{3}\left(g y_{3 n-1}, g x_{3 n-1}\right), \\
& g g x_{3 n+1}=g F_{1}\left(x_{3 n}, y_{3 n}\right)=F_{1}\left(g x_{3 n}, g y_{3 n}\right), \\
& g g y_{3 n+1}=g F_{1}\left(y_{3 n}, x_{3 n}\right)=F_{1}\left(g y_{3 n}, g x_{3 n}\right), \\
& g g x_{3 n+2}=g F_{2}\left(x_{3 n+1}, y_{3 n+1}\right)=F_{2}\left(g x_{3 n+1}, g y_{3 n+1}\right), \\
& g g y_{3 n+2}=g F_{2}\left(y_{3 n+1}, x_{3 n+1}\right)=F_{2}\left(g y_{3 n+1}, g x_{3 n+1}\right) .
\end{aligned}
$$


Thus, from condition (2.2), we have

$$
\begin{aligned}
G( & \left.g g x_{3 n}, g g x_{3 n+1}, F_{2}(x, y)\right) \\
= & G\left(F_{1}\left(g x_{3 n}, g y_{3 n}\right), F_{2}(x, y), F_{3}\left(g x_{3 n-1}, g y_{3 n-1}\right)\right) \\
\leq & a_{1} G\left(g g x_{3 n}, g x, g g x_{3 n-1}\right)+a_{2} G\left(g g y_{3 n}, g y, g g y_{3 n-1}\right)+a_{3} G\left(g g x_{3 n}, g x, g x\right) \\
& +a_{4} G\left(g g y_{3 n}, g y, g y\right)+a_{5} G\left(g x, g g x_{3 n-1}, g g x_{3 n-1}\right)+a_{6} G\left(g y, g g y_{3 n-1}, g g y_{3 n-1}\right) \\
& +a_{7} G\left(g g x_{3 n-1}, g g x_{3 n}, g g x_{3 n}\right)+a_{8} G\left(g g y_{3 n-1}, g g y_{3 n}, g g y_{3 n}\right) .
\end{aligned}
$$

Letting $n \rightarrow \infty$, using (2.11) and the fact that $G$ is continuous on its variables, we get that

$$
G\left(g x, g x, F_{2}(x, y)\right)=0 .
$$

Hence, $g x=F_{2}(x, y)$. Similarly, we may show that $g y=F_{2}(y, x)$. Also for the same reason, we may show that $g x=F_{1}(x, y), g y=F_{1}(y, x), g x=F_{3}(x, y)$ and $g y=F_{3}(y, x)$. Therefore, $(x, y)$ is a common coupled coincidence point of the pair $\left(F_{1}, g\right),\left(F_{2}, g\right)$ and $\left(F_{3}, g\right)$. By Lemma 2.1, we obtain

$$
g x=F_{1}(x, y)=F_{2}(x, y)=F_{3}(x, y)=F_{1}(y, x)=F_{2}(y, x)=F_{3}(y, x)=g y .
$$

Since the sequences $\left\{g x_{3 n-1}\right\},\left\{g x_{3 n}\right\}$ and $\left\{g x_{3 n+1}\right\}$ are all a subsequence of $\left\{g x_{n}\right\}$, then they are all G-convergent to $x$. Similarly, we may show that $\left\{g y_{3 n-1}\right\},\left\{g y_{3 n}\right\}$ and $\left\{g y_{3 n+1}\right\}$ are all G-convergent to $y$. From (2.2), we have

$$
\begin{aligned}
G\left(g x_{3 n}, g x, g x\right)= & G\left(F_{1}(x, y), F_{2}(x, y), F_{3}\left(x_{3 n-1}, y_{3 n-1}\right)\right) \\
\leq & a_{1} G\left(g x, g x, g x_{3 n-1}\right)+a_{2} G\left(g y, g y, g y_{3 n-1}\right)+a_{3} G(g x, g x, g x) \\
& +a_{4} G(g y, g y, g y)+a_{5} G\left(g x, g x_{3 n-1}, g x_{3 n-1}\right)+a_{6} G\left(g y, g y_{3 n-1}, g y_{3 n-1}\right) \\
& +a_{7} G\left(g x_{3 n-1}, g x, g x\right)+a_{8} G\left(g y_{3 n-1}, g y, g y\right) .
\end{aligned}
$$

Letting $n \rightarrow \infty$, and using the fact that $G$ is continuous on its variables, we get that

$$
G(x, g x, g x) \leq\left(a_{1}+a_{7}\right) G(g x, g x, x)+\left(a_{2}+a_{8}\right) G(g y, g y, y)+a_{5} G(g x, x, x)+a_{6} G(g y, y, y) .
$$

Similarly, we may show that

$$
G(y, g y, g y) \leq\left(a_{1}+a_{7}\right) G(g y, g y, y)+\left(a_{2}+a_{8}\right) G(g x, g x, x)+a_{5} G(g y, y, y)+a_{6} G(g x, x, x) .
$$

Thus, using the Proposition 1.10(iii), we have

$$
\begin{aligned}
G(x, g x, g x)+G(y, g y, g y) \leq & \left(a_{1}+a_{2}+a_{7}+a_{8}\right)[G(g x, g x, x)+G(g y, g y, y)] \\
& +\left(a_{5}+a_{6}\right)[G(g x, x, x)+G(g y, y, y)] \\
\leq & \left(a_{1}+a_{2}+2 a_{5}+2 a_{6}+a_{7}+a_{8}\right)[G(g x, g x, x)+G(g y, g y, y)] .
\end{aligned}
$$


Since $0 \leq a_{1}+a_{2}+a_{3}+a_{4}+2 a_{5}+2 a_{6}+a_{7}+a_{8}<1$, so the last inequality happens only if $G(x, g x, g x)=0$ and $G(y, g y, g y)=0$. Hence, $x=g x$ and $y=g y$. From (2.12), we have $x=g x=$ $g y=y$, thus, we get

$$
g x=F_{1}(x, x)=F_{2}(x, x)=F_{3}(x, x)=x .
$$

To prove the uniqueness, let $z \in X$ with $z \neq x$ such that

$$
z=g z=F_{1}(z, z)=F_{2}(z, z)=F_{3}(z, z)
$$

Again using condition (2.2) and Proposition 1.10(iii), we have

$$
\begin{aligned}
G(z, z, x)= & G\left(F_{1}(z, z), F_{2}(z, z), F_{3}(x, x)\right) \\
\leq & a_{1} G(g z, g z, g x)+a_{2} G(g z, g z, g x)+a_{3} G(g z, g z, g z)+a_{4} G(g z, g z, g z) \\
& +a_{5} G(g z, g x, g x)+a_{6} G(g z, g x, g x)+a_{7} G(g x, g z, g z)+a_{8} G(g x, g z, g z) \\
\leq & \left(a_{1}+a_{2}+2 a_{5}+2 a_{6}+a_{7}+a_{8}\right) G(z, z, x) .
\end{aligned}
$$

Since $0 \leq a_{1}+a_{2}+a_{3}+a_{4}+2 a_{5}+2 a_{6}+a_{7}+a_{8}<1$, we get $G(z, z, x)<G(z, z, x)$, which is a contradiction. Thus, $F_{1}, F_{2}, F_{3}$ and $g$ have a unique common fixed point.

Remark 2.1 Theorem 2.1 extends and improves Theorem 3.2 of Shatanawi [26].

The following corollary can be obtained from Theorem 2.1 immediately.

Corollary 2.1 Let $(X, G)$ be a G-metric space. Let $F_{1}, F_{2}, F_{3}: X \times X \rightarrow X$ and $g: X \rightarrow X$ be mappings such that

$$
G\left(F_{1}(x, y), F_{2}(u, v), F_{3}(w, z)\right) \leq a_{1} G(g x, g u, g w)+a_{2} G(g y, g v, g z)
$$

for all $x, y, u, v, w, z \in X$, where $a_{i} \geq 0, i=1,2$ and $a_{1}+a_{2}<1$. Suppose that $F_{1}, F_{2}, F_{3}$ and $g$ satisfy the following conditions:

(1) $F_{1}(X \times X) \subseteq g X, F_{2}(X \times X) \subseteq g X, F_{2}(X \times X) \subseteq g X$

(2) $g X$ is G-complete;

(3) $g$ is G-continuous and commutes with $F_{1}, F_{2}, F_{3}$.

Then there exist unique $x \in X$ such that

$$
g x=F_{1}(x, x)=F_{2}(x, x)=F_{3}(x, x)=x .
$$

Remark 2.2 If $F_{1}(x, y)=F_{2}(x, y)=F_{3}(x, y)$ and $a_{1}=a_{2}=k$, then Corollary 2.1 is reduced to Theorem 3.2 of Shatanawi [26].

Now, we give an example to support Corollary 2.1.

Example 2.1 Let $X=[0,1]$. Define $G: X \times X \times X \rightarrow \mathbb{R}^{+}$by

$$
G(x, y, z)=|x-y|+|y-z|+|z-x|
$$


for all $x, y, z \in X$. Then $(X, G)$ is a complete $G$-metric space. Define a map

$$
F_{1}, F_{2}, F_{3}: X \times X \rightarrow X
$$

by

$$
F_{1}(x, y)=F_{2}(x, y)=F_{3}(x, y)=\frac{x+y}{8}
$$

for all $x, y \in X$. Also, define $g: X \rightarrow X$ by $g x=\frac{x}{2}$ for $x \in X$. Then $F(X \times X) \subseteq g X$. Through calculation, we have

$$
\begin{aligned}
G & \left(F_{1}(x, y), F_{2}(u, v), F_{3}(w, z)\right) \\
& \leq G\left(\frac{x+y}{8}, \frac{u+v}{8}, \frac{w+z}{8}\right) \\
& =\frac{1}{8}(|x-u+y-v|+|u-w+v-z|+|w-x+z-y|) \\
& \leq \frac{1}{8}(|x-u|+|y-v|+|u-w|+|v-z|+|w-x|+|z-y|) \\
& =\frac{1}{4}(G(g x, g u, g w)+G(g y, g v, g z)) .
\end{aligned}
$$

Then the mappings $F_{1}, F_{2}, F_{3}$ and $g$ are satisfying condition (2.13) of Corollary 2.1 with $a_{1}=a_{2}=\frac{1}{4}$. So that all the conditions of Corollary 2.1 are satisfied. By Corollary 2.4, $F_{1}$, $F_{2}, F_{3}$ and $g$ have a unique common fixed point. Moreover, 0 is the unique common fixed point for all of the mappings $F_{1}, F_{2}, F_{3}$ and $g$.

If $a_{1}=a_{2}=0$, then Theorem 2.1 is reduced to the following.

Corollary 2.2 Let $(X, G)$ be a G-metric space. Let $F_{1}, F_{2}, F_{3}: X \times X \rightarrow X$ and $g: X \rightarrow X$ be four mappings such that

$$
\begin{aligned}
G\left(F_{1}(x, y), F_{2}(u, v), F_{3}(w, z)\right) \leq & c_{1} G(g x, g u, g u)+c_{2} G(g y, g v, g v) \\
& +c_{3} G(g u, g w, g w)+c_{4} G(g v, g z, g z) \\
& +c_{5} G(g w, g x, g x)+c_{6} G(g z, g y, g y)
\end{aligned}
$$

for all $x, y, u, v, w, z \in X$, where $c_{i} \geq 0, i=1,2, \ldots, 6$ and $c_{1}+c_{2}+2 c_{3}+2 c_{4}+c_{5}+c_{6}<1$. Suppose that $F_{1}, F_{2}, F_{3}$ and $g$ satisfy the following conditions:

(i) $F_{1}(X \times X) \subseteq g X, F_{2}(X \times X) \subseteq g X, F_{3}(X \times X) \subseteq g X$;

(ii) $g X$ is G-complete;

(iii) $g$ is G-continuous and commutes with $F_{1}, F_{2}, F_{3}$.

Then there exist unique $x \in X$ such that

$$
g x=F_{1}(x, x)=F_{2}(x, x)=F_{3}(x, x)=x .
$$

If we take $F_{1}(x, y)=F_{2}(x, y)=F_{3}(x, y)$ in Corollary 2.2, then the following corollary is obtained. 
Corollary 2.3 Let $(X, G)$ be a G-metric space. Let $F: X \times X \rightarrow X$ and $g: X \rightarrow X$ be four mappings such that

$$
\begin{aligned}
G(F(x, y), F(u, v), F(w, z)) \leq & c_{1} G(g x, g u, g u)+c_{2} G(g y, g v, g v) \\
& +c_{3} G(g u, g w, g w)+c_{4} G(g v, g z, g z) \\
& +c_{5} G(g w, g x, g x)+c_{6} G(g z, g y, g y)
\end{aligned}
$$

for all $x, y, u, v, w, z \in X$, where $c_{i} \geq 0, i=1,2, \ldots, 6$ and $c_{1}+c_{2}+2 c_{3}+2 c_{4}+c_{5}+c_{6}<1$. Suppose that $F$ and $g$ satisfy the following conditions:

(i) $F(X \times X) \subseteq g X$;

(ii) $g X$ is G-complete;

(iii) $g$ is G-continuous and commutes with $F$.

Then there exist unique $x \in X$ such that

$$
g x=F(x, x)=x .
$$

Now, we give an example to support Corollary 2.3.

Example 2.2 Let $X=[0,1]$. Define $G: X \times X \times X \rightarrow \mathbb{R}^{+}$by

$$
G(x, y, z)=|x-y|+|y-z|+|z-x|
$$

for all $x, y, z \in X$. Then $(X, G)$ is a complete $G$-metric space. Define a map $F: X \times X \rightarrow X$ by

$$
F(x, y)=\frac{x y}{8}
$$

for all $x, y \in X$. Also, define $g: X \rightarrow X$ by $g x=x$ for $x \in X$. Then $F(X \times X) \subseteq g X$. Through calculation, we have

$$
\begin{aligned}
G( & F(x, y), F(u, v), F(w, z)) \\
= & \frac{1}{8}(|x y-u v|+|u v-w z|+|w z-x y|) \\
\leq & \frac{1}{8}(|y||x-u|+|u||y-v|+|v||u-w|+|w||v-z|+|z||w-x|+|x||z-y|) \\
\leq & \frac{1}{8}(|x-u|+|y-v|+|u-w|+|v-z|+|w-x|+|z-y|) \\
= & \frac{1}{16}(G(g x, g u, g u)+G(g y, g v, g v)+G(g u, g w, g w)+G(g v, g z, g z) \\
& \left.+G(g w, g x, g x)+c_{6} G(g z, g y, g y)\right) .
\end{aligned}
$$

Then the mappings $F_{1}, F_{2}, F_{3}$ and $g$ are satisfying condition (2.15) of Corollary 2.3 with $c_{1}=c_{2}=c_{3}=c_{4}=c_{5}=c_{6}=\frac{1}{16}$. So that all the conditions of Corollary 2.3 are satisfied. By Corollary 2.3, $F$ and $g$ have a unique common fixed point. Moreover, 0 is the unique common fixed point for all of the mappings $F$ and $g$. 
If we take $F_{1}(x, y)=F_{2}(x, y)=F_{3}(x, y)$ in Theorem 2.1, then the following corollary is obtained.

Corollary 2.4 Let $(X, G)$ be a G-metric space. Let $F: X \times X \rightarrow X$ and $g: X \rightarrow X$ be mappings such that

$$
\begin{aligned}
G( & F(x, y), F(u, v), F(w, z)) \\
\leq & a_{1} G(g x, g u, g w)+a_{2} G(g y, g v, g z)+a_{3} G(g x, g u, g u) \\
& +a_{4} G(g y, g v, g v)+a_{5} G(g u, g w, g w)+a_{6} G(g v, g z, g z) \\
& +a_{7} G(g w, g x, g x)+a_{8} G(g z, g y, g y)
\end{aligned}
$$

for all $x, y, u, v, w, z \in X$, where $a_{i} \geq 0, i=1,2, \ldots, 8$ and $a_{1}+a_{2}+a_{3}+a_{4}+2 a_{5}+2 a_{6}+a_{7}+$ $a_{8}<1$. Suppose that $F$ and $g$ satisfy the following conditions:

(1) $F(X \times X) \subseteq g X$;

(2) $g X$ is G-complete;

(3) $g$ is G-continuous and commutes with $F$.

Then there exist unique $x \in X$ such that $g x=F(x, x)=x$.

Now, we introduce an example to support Corollary 2.4.

Example 2.3 Let $X=[-1,1]$. Define $G: X \times X \times X \rightarrow \mathbb{R}^{+}$by

$$
G(x, y, z)=|x-y|+|y-z|+|z-x|
$$

for all $x, y, z \in X$. Then $(X, G)$ is a complete $G$-metric space. Define a map

$$
F: X \times X \rightarrow X
$$

by

$$
F(x, y)=\frac{1}{16} x^{2}+\frac{1}{16} y^{2}-1
$$

for all $x, y \in X$. Also, define $g: X \rightarrow X$ by $g x=x$ for $x \in X$.

Clearly, we can get $F(X \times X)=\left[-1,-\frac{7}{8}\right] \subseteq g X$, and $g$ is $G$-continuous and commutes with $F$.

By the definition of the mappings of $F$ and $g$, for all $x, y, z, u, v, w \in[-1,1]$, we have

$$
\begin{aligned}
& G(F(x, y), F(u, v), F(w, z)) \\
& \quad \leq G\left(\frac{1}{16} x^{2}+\frac{1}{16} y^{2}-1, \frac{1}{16} u^{2}+\frac{1}{16} v^{2}-1, \frac{1}{16} w^{2}+\frac{1}{16} z^{2}-1\right) \\
& \quad=\frac{1}{16}\left(\left|x^{2}-u^{2}+y^{2}-v^{2}\right|+\left|u^{2}-w^{2}+v^{2}-z^{2}\right|+\left|w^{2}-x^{2}+z^{2}-y^{2}\right|\right) \\
& \quad \leq \frac{1}{16}\left(\left|x^{2}-u^{2}\right|+\left|y^{2}-v^{2}\right|+\left|u^{2}-w^{2}\right|+\left|v^{2}-z^{2}\right|+\left|w^{2}-x^{2}\right|+\left|z^{2}-y^{2}\right|\right) \\
& \quad \leq \frac{1}{16}(2|x-u|+2|y-v|+2|u-w|+2|v-z|+2|w-x|+2|z-y|)
\end{aligned}
$$




$$
\begin{aligned}
= & \frac{1}{16} G(g x, g u, g u)+\frac{1}{16} G(g y, g v, g v)+\frac{1}{16} G(g u, g w, g w) \\
& +\frac{1}{16} G(g v, g z, g z)+\frac{1}{16} G(g w, g x, g x)+\frac{1}{16} G(g z, g y, g y) .
\end{aligned}
$$

Then the mappings $F$ and $g$ are satisfying condition (2.16) of Corollary 2.4 with $a_{1}=a_{2}=0$, $a_{3}=a_{4}=a_{5}=a_{6}=a_{7}=a_{8}=\frac{1}{16}$. So that all the conditions of Corollary 2.4 are satisfied. By Corollary 2.4, $F$ and $g$ have a unique common fixed point. Here $x=4-2 \sqrt{6}$ is the unique common fixed point of mappings $F$ and $g$; that is, $F(x, x)=g x=x$.

\section{Application to integral equations}

Throughout this section, we assume that $X=C[0,1]$ is the set of all continuous functions defined on $[0,1]$. Define $G: X \times X \times X \rightarrow \mathbb{R}^{+}$by

$$
G(x, y, z)=\sup _{t \in[0,1]}|x(t)-y(t)|+\sup _{t \in[0,1]}|y(t)-z(t)|+\sup _{t \in[0,1]}|z(t)-x(t)|
$$

for all $x, y, z \in X$. Then $(X, G)$ is a $G$-complete metric space.

Consider the following integral equations:

$$
F_{i}(x, y)(t)=\int_{0}^{1} k(t, s)\left(f_{i}(s, x(s))+g_{i}(s, y(s))\right) d s, \quad t \in[0,1](i=1,2,3) .
$$

Next, we will analyze (3.1) under the following conditions:

(i) $k:[0,1] \times[0,1] \rightarrow \mathbb{R}^{+}$is continuous.

(ii) $f_{i}, g_{i}:[0,1] \times \mathbb{R} \rightarrow \mathbb{R}(i=1,2,3)$ are continuous functions.

(iii) There exist constants $\lambda_{i}, \mu_{i}>0(i=1,2,3)$ such that

$$
\left\{\begin{array} { l } 
{ | f _ { 1 } ( t , x ) - f _ { 2 } ( t , y ) | \leq \lambda _ { 1 } | x - y | , } \\
{ | f _ { 2 } ( t , x ) - f _ { 3 } ( t , y ) | \leq \lambda _ { 2 } | x - y | , } \\
{ | f _ { 3 } ( t , x ) - f _ { 1 } ( t , y ) | \leq \lambda _ { 3 } | x - y | }
\end{array} \text { and } \quad \left\{\begin{array}{l}
\left|g_{1}(t, x)-g_{2}(t, y)\right| \leq \mu_{1}|x-y|, \\
\left|g_{2}(t, x)-g_{3}(t, y)\right| \leq \mu_{2}|x-y|, \\
\left|g_{3}(t, x)-g_{1}(t, y)\right| \leq \mu_{3}|x-y|
\end{array}\right.\right.
$$

for all $t \in[0,1]$ and $x, y \in \mathbb{R}$.

(iv) $\|k\|_{\infty}\left(\max \left\{\lambda_{1}, \mu_{1}\right\}+2 \max \left\{\lambda_{2}, \mu_{2}\right\}+\max \left\{\lambda_{3}, \mu_{3}\right\}\right)<1$, where

$$
\|k\|_{\infty}=\sup \{k(t, s): t, s \in[0,1]\}
$$

The aim of this section is to give an existence theorem for a solution of the above integral equations by using the obtained result given by Theorem 2.1 .

Theorem 3.1 Under conditions (i)-(iv), integral equation (3.1) has a unique common solution in $C[0,1]$.

Proof First, we consider $F_{i}: X \times X \rightarrow X(i=1,2,3)$. By virtue of our assumptions, $F_{i}$ is well defined (this means that for $x, y \in X$ then $F_{i}(x, y) \in X(i=1,2,3)$ ). Then we can get

$$
\begin{aligned}
& G\left(F_{1}(x, y), F_{2}(u, v), F_{3}(w, z)\right) \\
& \quad=\sup _{t \in[0,1]}\left|F_{1}(x, y)-F_{2}(u, v)\right|+\sup _{t \in[0,1]}\left|F_{2}(u, v)-F_{3}(w, z)\right|+\sup _{t \in[0,1]}\left|F_{3}(w, z)-F_{1}(x, y)\right|
\end{aligned}
$$




$$
\begin{aligned}
= & \sup _{t \in[0,1]}\left|\int_{0}^{1} k(t, s)\left(f_{1}(s, x(s))+g_{1}(s, y(s))\right) d s-\int_{0}^{1} k(t, s)\left(f_{2}(s, u(s))+g_{2}(s, v(s))\right) d s\right| \\
& +\sup _{t \in[0,1]}\left|\int_{0}^{1} k(t, s)\left(f_{2}(s, u(s))+g_{2}(s, v(s))\right) d s-\int_{0}^{1} k(t, s)\left(f_{3}(s, w(s))+g_{3}(s, z(s))\right) d s\right| \\
& +\sup _{t \in[0,1]}\left|\int_{0}^{1} k(t, s)\left(f_{3}(s, w(s))+g_{3}(s, z(s))\right) d s-\int_{0}^{1} k(t, s)\left(f_{1}(s, x(s))+g_{1}(s, y(s))\right) d s\right| \\
= & \sup _{t \in[0,1]}\left|\int_{0}^{1} k(t, s)\left(\left(f_{1}(s, x(s))-f_{2}(s, u(s))\right)+\left(g_{1}(s, y(s))-g_{2}(s, v(s))\right)\right) d s\right| \\
& +\sup _{t \in[0,1]}\left|\int_{0}^{1} k(t, s)\left(\left(f_{2}(s, u(s))-f_{3}(s, w(s))\right)+\left(g_{2}(s, v(s))-g_{3}(s, z(s))\right)\right) d s\right| \\
& +\sup _{t \in[0,1]}\left|\int_{0}^{1} k(t, s)\left(\left(f_{3}(s, w(s))-f_{1}(s, x(s))\right)+\left(g_{3}(s, z(s))-g_{1}(s, y(s))\right)\right) d s\right| \\
\leq & \sup _{t \in[0,1]} \int_{0}^{1} k(t, s)\left(\left|f_{1}(s, x(s))-f_{2}(s, u(s))\right|+\left|g_{1}(s, y(s))-g_{2}(s, v(s))\right|\right) d s \\
& +\sup _{t \in[0,1]} \int_{0}^{1} k(t, s)\left(\left|f_{2}(s, u(s))-f_{3}(s, w(s))\right|+\left|g_{2}(s, v(s))-g_{3}(s, z(s))\right|\right) d s \\
& +\sup _{t \in[0,1]} \int_{0}^{1} k(t, s)\left(\left|f_{3}(s, w(s))-f_{1}(s, x(s))\right|+\left|g_{3}(s, z(s))-g_{1}(s, y(s))\right|\right) d s .
\end{aligned}
$$

By conditions (iii),

$$
\left\{\begin{array}{l}
\left|f_{1}(s, x(s))-f_{2}(s, u(s))\right| \leq \lambda_{1}|x(s)-u(s)|, \\
\left|f_{2}(s, u(s))-f_{3}(s, w(s))\right| \leq \lambda_{2}|u(s)-w(s)|, \\
\left|f_{3}(s, w(s))-f_{1}(s, x(s))\right| \leq \lambda_{3}|w(s)-x(s)|
\end{array}\right.
$$

and

$$
\left\{\begin{array}{l}
\left|g_{1}(s, y(s))-g_{2}(s, v(s))\right| \leq \mu_{1}|y(s)-v(s)| \\
\left|g_{2}(s, v(s))-g_{3}(s, z(s))\right| \leq \mu_{2}|v(s)-z(s)| \\
\left|g_{3}(s, z(s))-g_{1}(s, y(s))\right| \leq \mu_{3}|z(s)-y(s)|
\end{array}\right.
$$

Taking these inequalities into (3.2), we obtain

$$
\begin{aligned}
G( & \left.F_{1}(x, y), F_{2}(u, v), F_{3}(w, z)\right) \\
\leq & \sup _{t \in[0,1]} \int_{0}^{1} k(t, s)\left(\lambda_{1}|x(s)-u(s)|+\mu_{1}|y(s)-v(s)|\right) d s \\
& +\sup _{t \in[0,1]} \int_{0}^{1} k(t, s)\left(\lambda_{2}|u(s)-w(s)|+\mu_{2}|v(s)-z(s)|\right) \\
& \quad+\sup _{t \in[0,1]} \int_{0}^{1} k(t, s)\left(\lambda_{3}|w(s)-x(s)|+\mu_{3}|z(s)-y(s)|\right) \\
\leq & \max \left\{\lambda_{1}, \mu_{1}\right\} \sup _{t \in[0,1]} \int_{0}^{1} k(t, s)(|x(s)-u(s)|+|y(s)-v(s)|) d s
\end{aligned}
$$




$$
\begin{aligned}
& +\max \left\{\lambda_{2}, \mu_{2}\right\} \sup _{t \in[0,1]} \int_{0}^{1} k(t, s)(|u(s)-w(s)|+|v(s)-z(s)|) d s \\
& +\max \left\{\lambda_{3}, \mu_{3}\right\} \sup _{t \in[0,1]} \int_{0}^{1} k(t, s)(|w(s)-x(s)|+|z(s)-y(s)|) d s .
\end{aligned}
$$

Using the Cauchy-Schwartz inequality in (3.3), we get

$$
\begin{aligned}
& \int_{0}^{1} k(t, s)(|x(s)-u(s)|+|y(s)-v(s)|) d s \\
& \quad \leq\left(\int_{0}^{1} k^{2}(t, s) d s\right)^{\frac{1}{2}}\left(\int_{0}^{1}(|x(s)-u(s)|+|y(s)-v(s)|)^{2} d s\right)^{\frac{1}{2}} \\
& \quad \leq\|k\|_{\infty}\left(\sup _{t \in[0,1]}|x(t)-u(t)|+\sup _{t \in[0,1]}|y(t)-v(t)|\right) .
\end{aligned}
$$

Similarly, we can obtain the following estimate

$$
\begin{aligned}
& \int_{0}^{1} k(t, s)(|u(s)-w(s)|+|v(s)-z(s)|) d s \\
& \quad \leq\|k\|_{\infty}\left(\sup _{t \in[0,1]}|u(t)-w(t)|+\sup _{t \in[0,1]}|v(t)-z(t)|\right), \\
& \int_{0}^{1} k(t, s)(|w(s)-x(s)|+|z(s)-y(s)|) d s \\
& \quad \leq\|k\|_{\infty}\left(\sup _{t \in[0,1]}|w(t)-x(t)|+\sup _{t \in[0,1]}|z(t)-y(t)|\right) .
\end{aligned}
$$

Substituting (3.4), (3.5) and (3.6) into (3.3), we obtain that

$$
\begin{aligned}
G( & \left.F_{1}(x, y), F_{2}(u, v), F_{3}(w, z)\right) \\
\leq & \max \left\{\lambda_{1}, \mu_{1}\right\}\|k\|_{\infty}\left(\sup _{t \in[0,1]}|x(t)-u(t)|+\sup _{t \in[0,1]}|y(t)-v(t)|\right) \\
& +\max \left\{\lambda_{2}, \mu_{2}\right\}\|k\|_{\infty}\left(\sup _{t \in[0,1]}|u(t)-w(t)|+\sup _{t \in[0,1]}|v(t)-z(t)|\right) \\
& +\max \left\{\lambda_{3}, \mu_{3}\right\}\|k\|_{\infty}\left(\sup _{t \in[0,1]}|w(t)-x(t)|+\sup _{t \in[0,1]}|z(t)-y(t)|\right) \\
= & \frac{1}{2} \max \left\{\lambda_{1}, \mu_{1}\right\}\|k\|_{\infty} \cdot 2 \sup _{t \in[0,1]}|x(t)-u(t)| \\
& +\frac{1}{2} \max \left\{\lambda_{1}, \mu_{1}\right\}\|k\|_{\infty} \cdot 2 \sup _{t \in[0,1]}|y(t)-v(t)| \\
& +\frac{1}{2} \max \left\{\lambda_{2}, \mu_{2}\right\}\|k\|_{\infty} \cdot 2 \sup _{t \in[0,1]}|u(t)-w(t)| \\
& +\frac{1}{2} \max \left\{\lambda_{2}, \mu_{2}\right\}\|k\|_{\infty} \cdot 2 \sup _{t \in[0,1]}|v(t)-z(t)| \\
& +\frac{1}{2} \max \left\{\lambda_{3}, \mu_{3}\right\}\|k\|_{\infty} \cdot 2 \sup _{t \in[0,1]}|w(t)-x(t)| \\
& +\frac{1}{2} \max \left\{\lambda_{3}, \mu_{3}\right\}\|k\|_{\infty} \cdot 2 \sup _{t \in[0,1]}|z(t)-y(t)|
\end{aligned}
$$




$$
\begin{aligned}
= & \frac{1}{2} \max \left\{\lambda_{1}, \mu_{1}\right\}\|k\|_{\infty} G(x, u, u)+\frac{1}{2} \max \left\{\lambda_{1}, \mu_{1}\right\}\|k\|_{\infty} G(y, v, v) \\
& +\frac{1}{2} \max \left\{\lambda_{2}, \mu_{2}\right\}\|k\|_{\infty} G(u, w, w)+\frac{1}{2} \max \left\{\lambda_{2}, \mu_{2}\right\}\|k\|_{\infty} G(v, z, z) \\
& +\frac{1}{2} \max \left\{\lambda_{3}, \mu_{3}\right\}\|k\|_{\infty} G(w, x, x)+\frac{1}{2} \max \left\{\lambda_{3}, \mu_{3}\right\}\|k\|_{\infty} G(z, y, y) .
\end{aligned}
$$

Taking $g x=x$ for all $x \in X$, and

$$
\begin{aligned}
& a_{1}=a_{2}=0, \quad a_{3}=a_{4}=\frac{1}{2} \max \left\{\lambda_{1}, \mu_{1}\right\}\|k\|_{\infty}, \\
& a_{5}=a_{6}=\frac{1}{2} \max \left\{\lambda_{2}, \mu_{2}\right\}\|k\|_{\infty}, \quad a_{7}=a_{8}=\frac{1}{2} \max \left\{\lambda_{3}, \mu_{3}\right\}\|k\|_{\infty},
\end{aligned}
$$

then inequality (3.7) becomes

$$
\begin{aligned}
G\left(F_{1}(x, y), F_{2}(u, v), F_{3}(w, z)\right) \leq & a_{1} G(g x, g u, g w)+a_{2} G(g y, g v, g z)+a_{3} G(g x, g u, g u) \\
& +a_{4} G(g y, g v, g v)+a_{5} G(g u, g w, g w)+a_{6} G(g v, g z, g z) \\
& +a_{7} G(g w, g x, g x)+a_{8} G(g z, g y, g y) .
\end{aligned}
$$

By condition (iv), we know that

$$
\begin{aligned}
a_{1} & +a_{2}+a_{3}+a_{4}+2\left(a_{5}+a_{6}\right)+a_{7}+a_{8} \\
& =\|k\|_{\infty}\left(\max \left\{\lambda_{1}, \mu_{1}\right\}+2 \max \left\{\lambda_{2}, \mu_{2}\right\}+\max \left\{\lambda_{3}, \mu_{3}\right\}\right)<1 .
\end{aligned}
$$

This proves that the operator $F_{i}(i=1,2,3)$ and $g=I$ satisfy contractive condition (2.2) appearing in Theorem 2.1 with $g=I$. Therefore, $F_{1}, F_{2}, F_{3}$ have a unique common coupled fixed point, that is, $F_{1}(x, x)=F_{2}(x, x)=F_{3}(x, x)=x$, and so, $(x, x)$ is the unique solution of equation (3.1).

\section{Competing interests}

The authors declare that they have no competing interests.

\section{Authors' contributions}

Both authors contributed equally to this work. Both authors read and approved the final manuscript.

\section{Acknowledgements}

The authors are grateful to the editor and the reviewer for suggestions which improved the contents of the article. This work is supported by the National Natural Science Foundation of China (11271105), the Natural Science Foundation of Zhejiang Province (Y6110287, LY12A01030) and the Physical Experiment Center of Hangzhou Normal University.

Received: 8 June 2013 Accepted: 19 September 2013 Published: 07 Nov 2013

\section{References}

1. Abbas, M, Jungck, G: Common fixed point results for noncommuting mappings without continuity in cone metric spaces. J. Math. Anal. Appl. 341, 416-420 (2008)

2. Abdeljawad, T: Completion of cone metric spaces. Hacet. J. Math. Stat. 39, 67-74 (2010)

3. Beg, I, Abbas, M: Coincidence point and invariant approximation for mappings satisfying generalize weak contractive condition. Fixed Point Theory Appl. 2006, Article ID 74503 (2006)

4. Haung, LG, Zhang, X: Cone metric spaces and fixed point theorems of contractive mappings. J. Math. Anal. Appl. 332, 1468-1476 (2007)

5. Jungck, G: Compatible mappings and common fixed points. Int. J. Math. Math. Sci. 9(4), 771-779 (1986)

6. Jungck, G: Common fixed points for commuting and compatible maps on compacta. Proc. Am. Math. Soc. 103, 977-983 (1988) 
7. Jungck, G, Hussain, N: Compatible maps and invariant approximations. J. Math. Anal. Appl. 325(2), 1003-1012 (2007)

8. Popa, V, Mocanu, M: Altering distance and common fixed points under implicit relations. Hacet. J. Math. Stat. 38 329-337 (2009)

9. Sahin, I, Telci, M: Fixed points of contractive mappings on complete cone metric spaces. Hacet. J. Math. Stat. 38, 59-67 (2009)

10. Bhaskar, TG, Lakshmikantham, GV: Fixed point theorems in partially ordered metric spaces and applications. Nonlinear Anal. 65, 1379-1393 (2006)

11. Lakshmikantham, V, Ćirić, LB: Coupled fixed point theorems for nonlinear contractions in partially ordered metric spaces. Nonlinear Anal. 70, 4341-4349 (2009)

12. Sedghi, S, Altun, I, Shobe, N: Coupled fixed point theorems for contractions in fuzzy metric spaces. Nonlinear Anal. 72, 1298-1304 (2010)

13. Shatanawi, W: Some common coupled fixed point results in cone metric spaces. Int. J. Math. Anal. 4(48), 2381-2388 (2010)

14. Mustafa, Z, Sims, B: A new approach to generalized metric spaces. J. Nonlinear Convex Anal. 7(2), $289-297$ (2006)

15. Abbas, M, Rhoades, BE: Common fixed point results for noncommuting mapping without continuity in generalized metric spaces. Appl. Math. Comput. 215, 262-269 (2009)

16. Gu, F: Common fixed point theorems for six mappings in generalized metric spaces. Abstr. Appl. Anal. 2012, Article ID 379212 (2012). doi:10.1155/2012/379212

17. $\mathrm{Gu}, \mathrm{F}, \mathrm{Ye}, \mathrm{H}$ : Common fixed point theorems of Altman integral type mappings in G-metric spaces. Abstr. Appl. Anal. 2012, Article ID 630457 (2012). doi:10.1155/2012/630457

18. Gu, F: Some new common coupled fixed point results in two generalized metric spaces. Fixed Point Theory Appl. 2013, 181 (2013). doi:10.1186/1687-1812-2013-181

19. Gu, F, Yang, Z: Some new common fixed point results for three pairs of mappings in generalized metric spaces. Fixed Point Theory Appl. 2013, 174 (2013). doi:10.1186/1687-1812-2013-174

20. Gu, F, Yin, Y: Common fixed point for three pairs of self-maps satisfying common (E.A) property in generalized metric spaces. Abstr. Appl. Anal. 2013, Article ID 808092 (2013). doi:10.1155/2013/808092

21. Mustafa, Z, Shatanawi, W, Bataineh, M: Existence of fixed point results in G-metric spaces. Int. J. Math. Math. Sci. 2009, Article ID 283028 (2009)

22. Mustafa, Z, Obiedat, H, Awawdeh, F: Some common fixed point theorem for mapping on complete G-metric spaces. Fixed Point Theory Appl. 2008, Article ID 189870 (2008)

23. Shatanawi, W: Common fixed point result for two self-maps in G-metric space. Mat. Vesn. 65(2), 143-150 (2013)

24. Shatanawi, W: Some fixed point theorems in ordered G-metric spaces and applications. Abstr. Appl. Anal. 2011, Article ID 126205 (2011). doi:10.1155/2011/126205

25. Shatanawi, W: Fixed point theory for contractive mappings satisfying $\Phi$-maps in G-metric spaces. Fixed Point Theory Appl. 2010, Article ID 181650 (2010). doi:10.1155/2010/181650

26. Shatanawi, W: Coupled fixed point theorems in generalized metric spaces. Hacet. J. Math. Stat. 40(3), $441-447$ (2011)

27. $\mathrm{Ye}, \mathrm{H}, \mathrm{Gu}, \mathrm{F}$ : Common fixed point theorems for a class of twice power type contraction maps in G-metric spaces. Abstr. Appl. Anal. 2012, Article ID 736214 (2012). doi:10.1155/2012/736214

28. $\mathrm{Ye}, \mathrm{H}, \mathrm{Lu}, \mathrm{J}, \mathrm{Gu}, \mathrm{F}$ : A new common fixed point theorem for noncompatible mappings of type $\left(A_{f}\right)$ in $\mathrm{G}$-metric space. J. Hangzhou Norm. Univ. 11(6), 511-515 (2012)

29. Yin, Y, Gu, F: Common fixed point theorem about four mappings in G-metric spaces. J. Hangzhou Norm. Univ. 12(1), 50-56 (2013)

30. Zhou, S, Gu, F: Some new fixed point theorems in G-metric spaces. J. Hangzhou Norm. Univ. 11(1), 47-50 (2012)

31. Shatanawi, W, Postolache, M: Some fixed point results for a G-weak contraction in G-metric spaces. Abstr. Appl. Anal. 2012, Article ID 815870 (2012). doi:10.1155/2012/815870

32. Aydi, H, Karapinar, E, Shatanawi, W: Tripled common fixed point results for generalized contractions in ordered generalized metric spaces. Fixed Point Theory Appl. 2012, 101 (2012)

33. Tahat, N, Aydi, H, Karapinar, E, Shatanawi, W: Common fixed points for single-valued and multi-valued maps satisfying a generalized contraction in G-metric spaces. Fixed Point Theory Appl. 2012, 48 (2012). doi:10.1186/1687-1812-2012-48

34. Aydi, H, Damjanović, B, Samet, B, Shatanawi, W: Coupled fixed point theorems for nonlinear contractions in partially ordered G-metric spaces. Math. Comput. Model. 54(9-10), 2443-2450 (2011)

35. Choudhury, BS, Maity, P: Coupled fixed point results in generalized partially ordered G-metric spaces. Math. Comput. Model. 54, 73-79 (2011)

36. Gu, F, Zhou, S: Coupled common fixed point theorems for a pair of commuting mappings in partially ordered G-metric spaces. Fixed Point Theory Appl. 2013, 64 (2013). doi:10.1186/1687-1812-2013-64

37. Luong, NV, Thuan, NX: Coupled fixed point theorems in partially ordered G-metric spaces. Math. Comput. Model. 55(3-4), 1601-1609 (2012)

38. Saadati, R, Vaezpour, SM, Vetro, P, Rhoades, BE: Fixed point theorems in generalized partially ordered G-metric spaces. Math. Comput. Model. 52(5-6), 797-810 (2010)

39. Gholizadeh, L, Saadati, R, Shatanawi, W, Vaezpour, SM: Contractive mapping in generalized, ordered metric spaces with application in integral equations. Math. Probl. Eng. 2011, Article ID 380784 (2011). doi:10.1155/2011/380784

10.1186/1687-1812-2013-266

Cite this article as: Gu and Yin: A new common coupled fixed point theorem in generalized metric space and applications to integral equations. Fixed Point Theory and Applications 2013, 2013:266 